\title{
Alternative techniques for pedicle transfer of an island flap and a free flap
}

\author{
Dale A Classen MD FRCSC
}

DA Classen. Alternative techniques for pedicle transfer of an island flap and a free flap. Can J Plast Surg 2005;13(2):77-81.

\section{Techniques alternatives pour le transfert d'un pédicule dans un greffon en îlot et un lambeau libre}

Les techniques alternatives de transfert de pédicule dans un lambeau radial inverse à l'avant-bras pour couverture de la main et d'un lambeau libre myocutané du grand dorsal pour couverture d'une plaie pelvienne sont illustrées ici. L'extériorisation du pédicule vasculaire pour un lambeau radial inverse à l'avant-bras permet un plus grand arc de mouvement du lambeau pour une couverture plus distale et évite le compromis vasculaire potentiel d'un tunnel sous un pont cutané resserré. Un transfert en deux étapes du lambeau libre myocutané du grand dorsal sur un pédicule porteur au niveau du poignet peut être utile lorsque les vaisseaux receveurs locaux ne sont pas adéquats pour un transfert de lambeau libre. Bien que ces deux modifications du pédicule vasculaire aient leurs inconvénients, elles peuvent être utiles dans certaines circonstances. Leurs avantages et leurs limites sont présentés ici.

\section{Key Words: Free flap; Island flap; Pedicle}

$\mathrm{T}$

he vascularity of a flap through its pedicle must be assured

for its successful transfer. An island flap may suffer vascular compromise by excessive tension on the pedicle by stretching the pedicle beyond its arc of rotation, or by compression from the overlying skin bridge. A free flap must have adequate local recipient vessels for anastomosis. Most wounds requiring coverage with an island or free flap can be reconstructed in a fairly standard fashion. There are, however, rare situations in which technical modifications of pedicle transfer may be useful for island or free flap transfer. Pedicle modification of the reverse radial forearm flap, by leaving the pedicle exterior to the skin bridge, increases the arc of rotation and avoids pedicle compression. Transfer of a free flap on a wrist carrier obviates the requirement for local recipient vessels. These alternative techniques of pedicle transfer have been previously described in the literature. They are presented here as a reminder to the surgeon faced with a difficult wound for reconstruction when an island flap pedicle may not reach a defect, or local recipient vessels are inadequate for free flap transfer.

\section{CASE PRESENTATIONS}

Case 1: Exteriorization of the pedicle of a reverse radial forearm island flap

The vascular pedicle of the reverse radial forearm flap may be left external to a skin bridge and subsequently divided at a second stage. The application of this principle is illustrated in the following case of a patient with fourth-degree friction burns on the dorsum of his fingers.

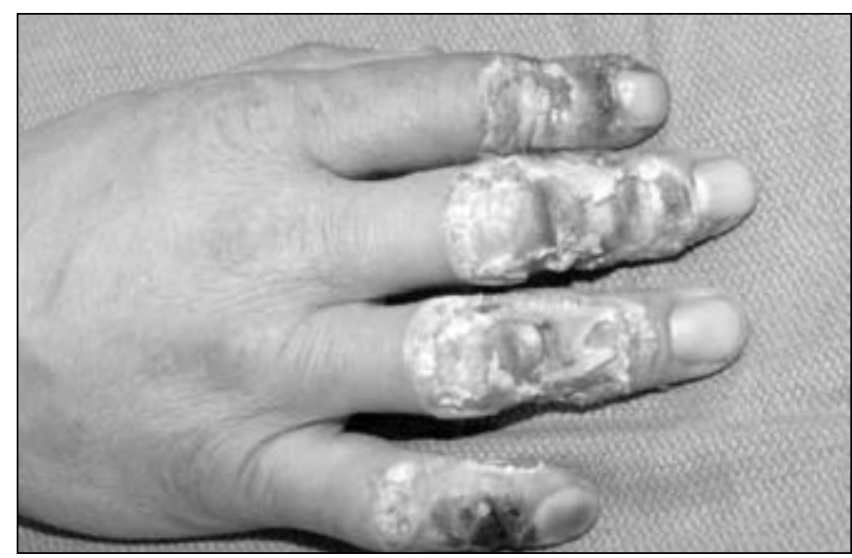

Figure 1) Fourth-degree friction burns on the dorsum of the fingers

A 50-year-old man caught his right dominant hand in a belt and pulley. He suffered fourth-degree burns on the dorsum of his index, long, ring and little fingers from the proximal interphalangeal joints to beyond the distal interphalangeal (DIP) joints (Figure 1). There were no underlying fractures. In the first operation, the wounds were debrided and the tendons were preserved. A reverse radial forearm flap measuring $7 \mathrm{~cm} \times$ $5 \mathrm{~cm}$ was designed and elevated to cover the wounds of the long, ring and little fingers (Figure 2). To ensure no tension on the pedicle, and to allow direct inset of the flap over the defect, 


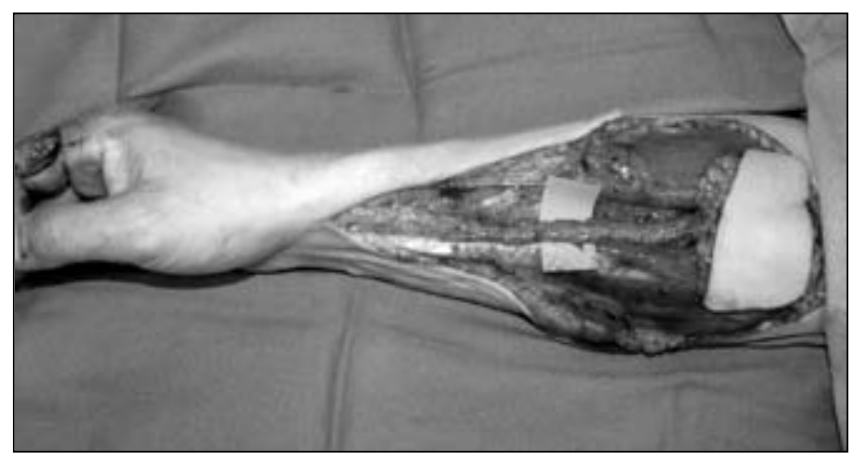

Figure 2) Reverse radial forearm flap before transfer

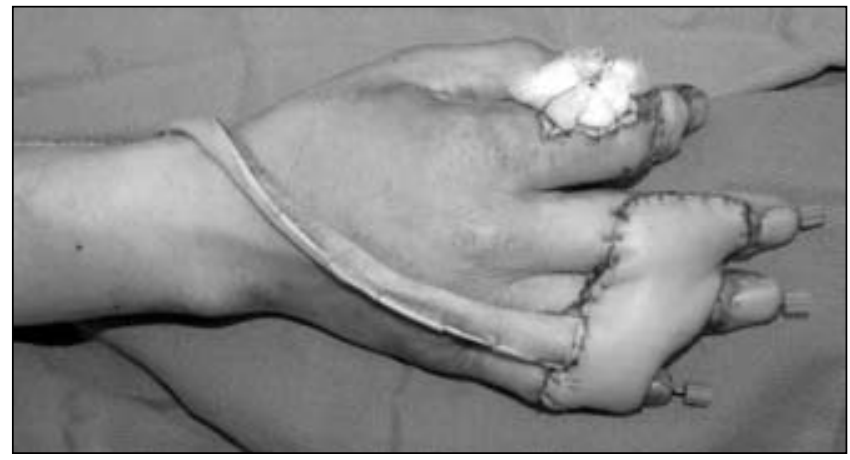

Figure 3) Transferred reverse radial forearm flap with exteriorized skin-grafted pedicle

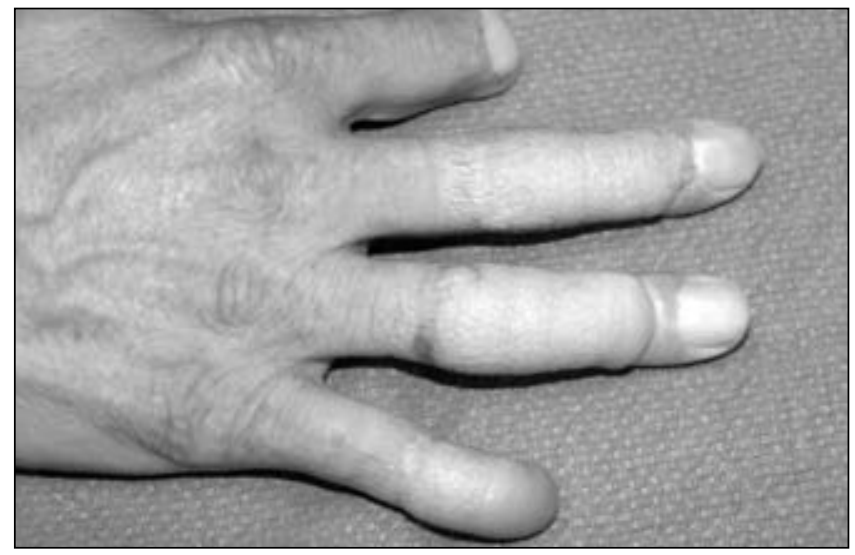

Figure 4) Five-month postoperative view

the pedicle of the flap (the radial artery and the venae comitantes veins) was left exterior to the hand (Figure 3). A splitthickness skin graft was wrapped around the pedicle from the flap to the wrist. This was protected with a volar splint and moist dressings. A reverse homodigital artery flap was designed and transferred for coverage of the index finger.

Early range of motion was allowed of the wrist and metacarpophalangeal joints beginning a few days postoperatively.

At 25 days postoperatively, the patient returned to the operating room for division of the pedicle. A clamp was initially applied to temporarily occlude the artery, ensuring that adequate neovascularization had occurred. The vascular pedicle was excised. The local flap at the index finger had become

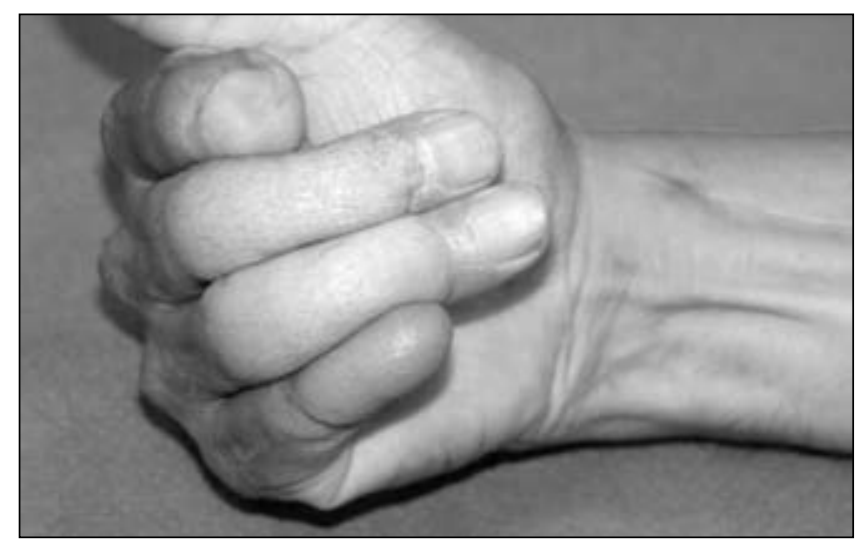

Figure 5) Five-month postoperative view

necrotic and the index finger was subsequently amputated at the proximal interphalangeal joint. The little finger developed an exposed DIP joint and was shortened at the DIP joint level.

Nine weeks postoperatively, the flap was divided between the long and ring fingers. Subsequently, one month later, the flap was divided between the ring and little fingers. Follow-up at five months is shown in Figures 4 and 5.

\section{Case 2: Free-flap transfer via a wrist carrier pedicle}

Free-flap transfer with first-stage revascularization at the level of the wrist, and a subsequent second-stage division of this pedicle is illustrated in the following patient with a hemipelvectomy wound.

A 73-year-old man presented to the emergency room in septic shock secondary to clostridial myonecrosis of his right lower extremity. He had a $24 \mathrm{~h}$ history of cyanosis developing in the right thigh and hip region. On presentation, he had subcutaneous emphysema from the groin to the ankle. As a lifesaving measure, a hip disarticulation was performed. Cultures from the wound and blood were positive for Clostridium septicum, which had arisen from a previously unrecognized colon cancer.

An initial attempt at closure of the wound with skin grafts was unsuccessful due to secondary infection with Pseudomonas, and poor vascularization of the wound. Subsequent repeat debridements were performed. Flap transfer was required for coverage of the exposed pelvis (Figure 6). There were no local recipient vessels available because the exposed external iliac artery and vein were ligated in the base of the wound. Consideration was given to a free flap with a vein graft extension to the contralateral femoral vessels. However, the vein grafts available were thought to be of poor quality. Wound coverage was achieved by transfer of the ipsilateral latissimus dorsi myocutaneous flap by revascularization to the radial artery and cephalic vein at the level of the wrist (Figure 7). The proximal portion of the latissimus muscle was wrapped around the vascular pedicle for protection and covered with a split-thickness skin graft (Figure 8).

Intermittent ischemia with a forearm tourniquet was performed postoperatively to (theoretically) promote neovascularization. The vascular pedicle was divided 38 days postoperatively. There was some minor superficial ischemia, which occurred postoperatively. Successful wound coverage was achieved. Three month postoperative view is shown in Figures 9 and 10. 


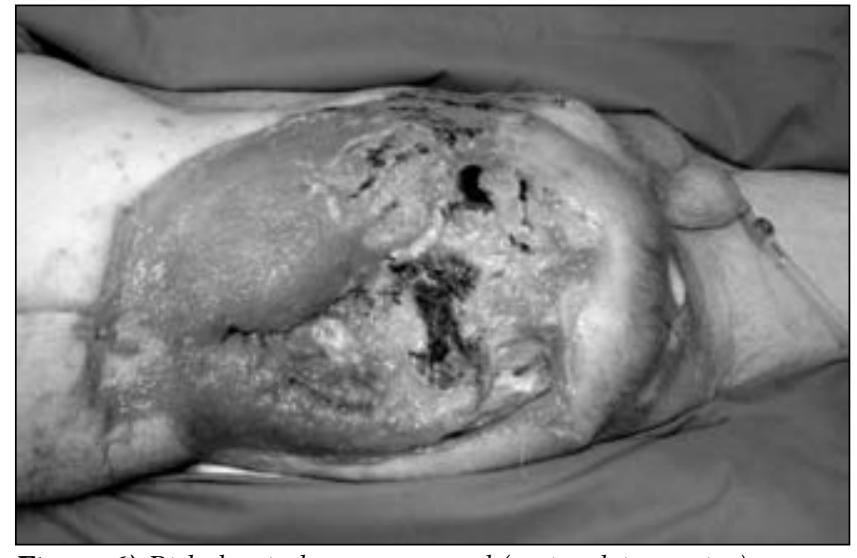

Figure 6) Right hemipelvectomy wound (patient lying supine)

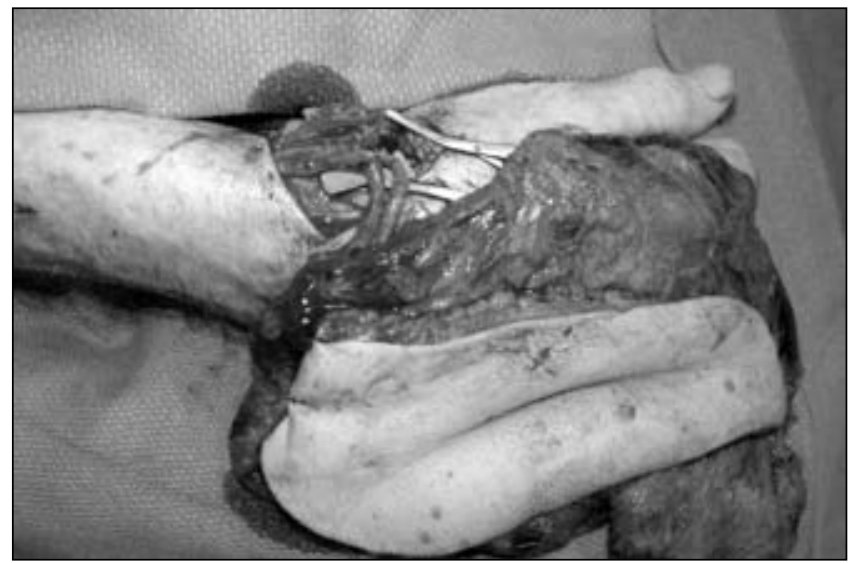

Figure 7) Latissimus myocutaneous flap revascularized to the radial artery and cephalic vein in the snuff box of right wrist

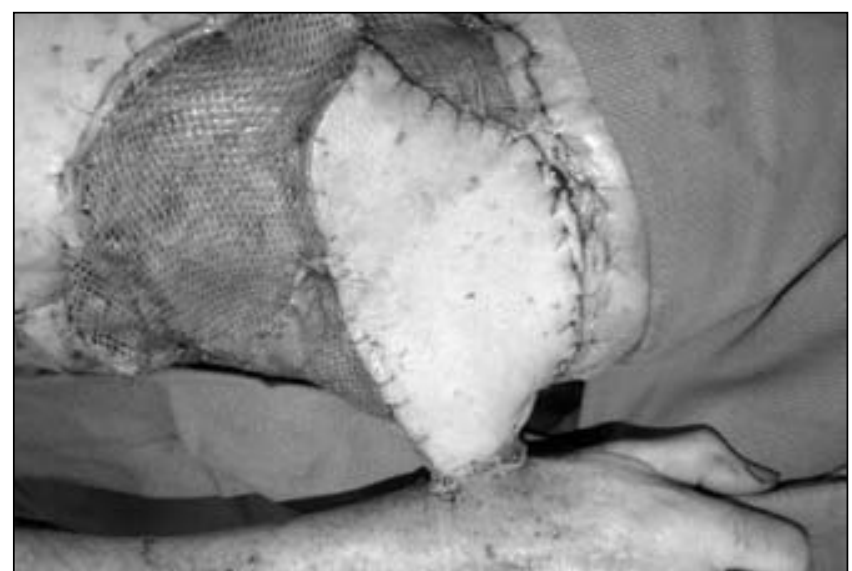

Figure 8) Latissimus myocutaneous flap inset, attached to wrist

\section{DISCUSSION}

Exteriorization of the vascular pedicle of an island flap Transfer of an island flap isolates the vascular pedicle, allowing movement of the flap without detachment of the pedicle. The standard method of transferring an island flap tunnels the vascular pedicle under intact skin to protect the vascular pedicle of the flap. However, there may be circumstances when the vascular pedicle becomes compromised under a tight skin bridge, or does not reach the defect without undue tension on

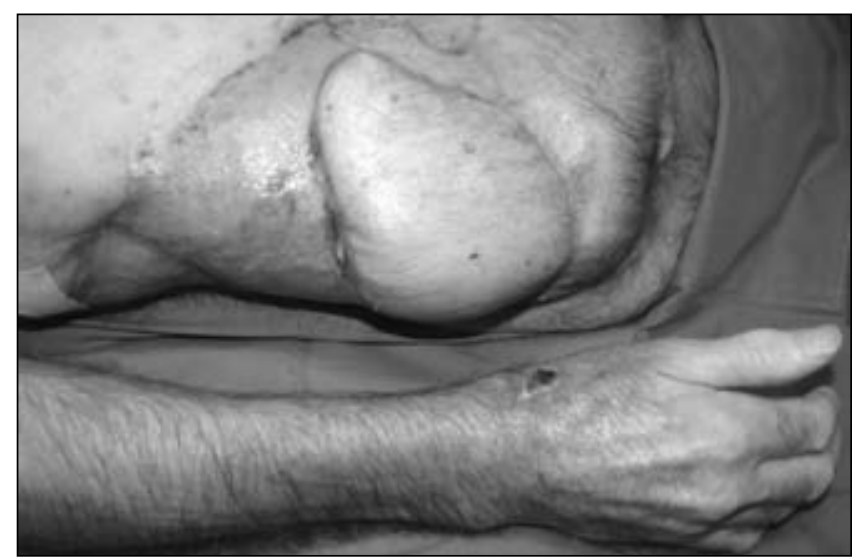

Figure 9) Three-month postoperative view (patient lying supine)

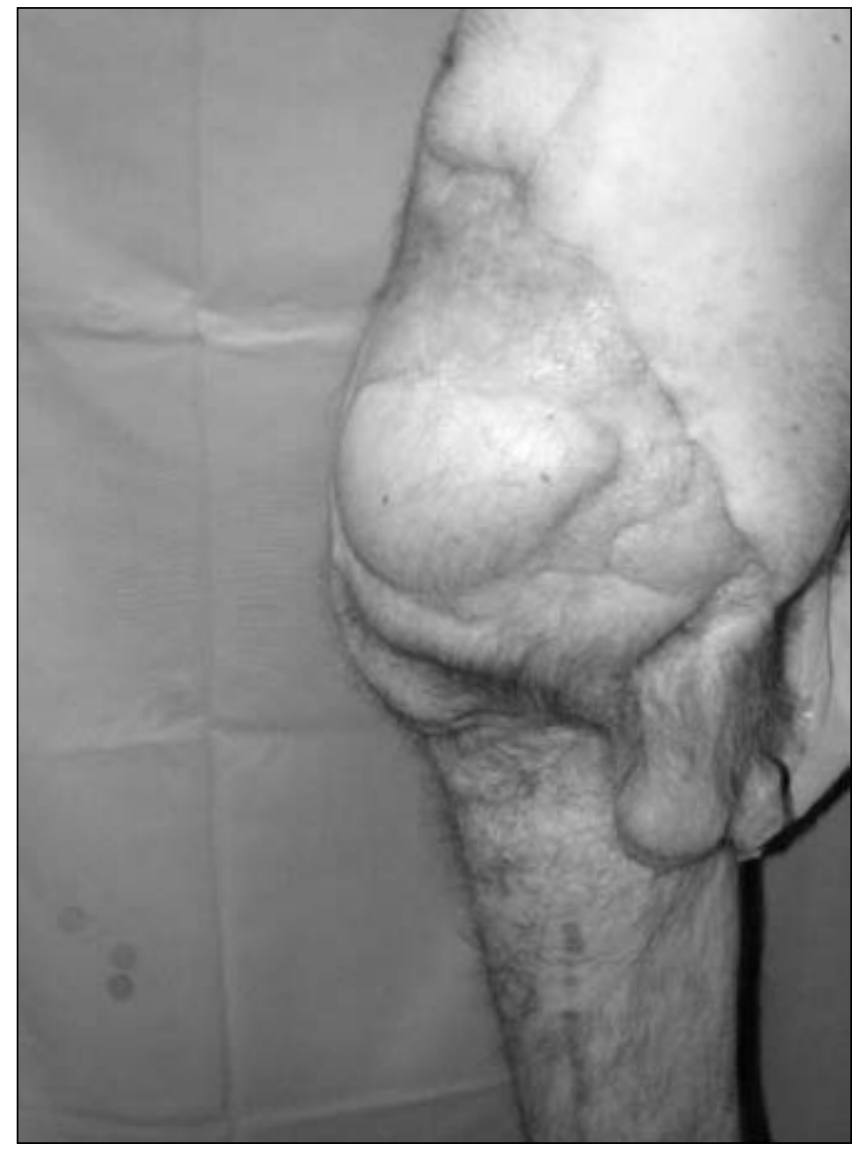

Figure 10) Three-month postoperative view (patient standing)

the vascular supply. In these circumstances, exteriorizing the vascular pedicle (ie, placing the pedicle external to the skin), may aid with flap inset without compromise of the blood supply. At a second stage, division of the exteriorized pedicle is performed with the island flap surviving based on neovascularization from the wound bed.

Govila (1-5) and Govila and Chhajer (6) have used the term "extracorporeal transfer" when the pedicle of an island flap is transferred external to the skin. Govila described his 12-year experience with extracorporeal flaps (7). Olding (8) reported a single case of reverse radial forearm flap with exteriorization of the pedicle for soft-tissue coverage of multiple digital amputations. 
Brunelli et al (9) described lengthening the pedicle of a reverse posterior interosseous flap by exteriorization of the pedicle for coverage of defects on the dorsal hand and first web space. Successful coverage was achieved in all three cases with division of the exteriorized pedicle between three and four weeks post-transfer.

The reverse radial forearm flap is a well-established flap for a wide variety of hand injuries (10). The use of this flap in the hand is limited by the length of the vascular pedicle, and by the tunnelling of the pedicle required to reach the defect. In case 1, exteriorization of the pedicle allowed the flap to reach this very distal defect in the hand. Other options for reconstruction were considered. A groin flap would have provided bulky coverage and the hand would have been in a dependent position. A free flap for coverage, such as a serratus muscle or temporoparietal fascia, was also considered, but would have necessitated significant excision of normal undamaged skin for flap inset.

\section{Free flap transfer via a wrist carrier pedicle}

A free flap requires adequate recipient vessel inflow and outflow to ensure its survival. If recipient vessels are inadequate due to disease or trauma, the standard technique is to use vein grafts to reach appropriate vessels, or flap modifications to extend the pedicle (11). There may be situations were local recipient vessels are inadequate and vein grafts are not an option. In these situations, a free-flap transfer may still be performed by revascularizing the flap to carrier vessels at a site remote from the wound. The flap is allowed to establish vascular ingrowth from the wound over the course of a few weeks from the wound bed and peripheral margins. The free-flap pedicle is then subsequently divided from the carrier vessels. The free flap will survive based on neovascularization from the wound. This modification of a free flap pedicle was first described by Taylor et al (12), with a free osteocutaneous groin flap anastomosed to the posterior tibial vessels of the opposite leg for a compound leg defect. There have been numerous reports (13-16) describing cross-leg free flaps for lower extremity wounds for both soft tissue and bony defects when there is inadequate vasculature in the affected limb.

Lower extremity wounds are the most common indication for transfer of a free flap on carrier vessels. However, there are other situations, such as the patient described above, who do not have any local recipient vessels, and vein graft options are limited or nonexistent. Brenman et al (17) described two freeflap transfers using the wrist as a carrier for reconstruction of a hip wound in one patient and a leg wound in another. Morrison and Pribaz (18) described the transfer of a groin flap to a lower extremity wound on a wrist carrier pedicle. O'Brien et al (19) described the transfer of a scapular flap to a hip wound based on the wrist as a vascular carrier. Harris et al (20) described three patients with posterior torso and pelvic wounds reconstructed with free flaps based on a wrist carrier.

The patient described in case 2 had a relatively avascular wound base, consisting of essentially devascularized bone. To potentially enhance peripheral neovascularization of the free latissimus flap, two technical details were performed. A skin paddle was taken with the latissimus flap and inset along a portion of the wound. This may enhance neovascularization from the margins (21). Serial occlusion of the vascular inflow to the flap was performed beginning at two weeks postoperatively by inflation of an arm tourniquet to promote ischemia in the flap. Ischemic preconditioning of the flap may enhance neovascularization between the flap and recipient bed (22). Experimental studies $(21,23)$ in animal models have demonstrated adequate peripheral neovascularization for flap survival between five and eight days. However, there are reports of necrosis of a free flap with late injury to the vascular pedicle $(24,25)$. Ischemic recipient beds may be unable to provide adequate neovascularization. This must be kept in mind when considering this method of flap transfer.

The alternative techniques for pedicle transfer of an island flap and a free flap as described were extremely useful in the two presented cases. However, they both have three disadvantages compared with standard transfer in a single stage. The first is a necessity for a second-stage division of the pedicle. Although division of the pedicle is a minor procedure, it is necessary to complete the reconstruction. The second disadvantage is the time it takes to complete the reconstruction. During this time, there is potential for iatrogenic injury to the exposed pedicle. The third disadvantage is the fact that the axial blood supply to the flap is sacrificed. The flap must become dependent on neovascularization from the wound for its survival. Despite these disadvantages, both techniques as discussed are viable and valuable options in limited circumstances.

\section{REFERENCES}

1. Govila A. Extracorporeal tissue transfer for extensive facial defects. Br J Plast Surg 1989;42:521-5.

2. Govila A. Non-microsurgical extracorporeal distant tissue transfer. Eur J Plast Surg 1989;12:99-102.

3. Govila A. Extracorporeal tissue transfer for salvage replantation. Acta Chir Plast 1992;34:148-56.

4. Govila A. Reconstruction of penis by prefabrication on forearm. Acta Chir Plast 1993;35:125-30.

5. Govila A. Extracorporeal tissue transfer for intra-oral reconstructions. Br J Plast Surg 1992;45:388-90.

6. Govila A, Chhajer PK. Extracorporeal fascia-fat flap for restoration of facial contour in progressive hemifacial atrophy. Br J Plast Surg 1994;47:54-6.

7. Govila A. An alternative free flap technique and 12-year follow-up. J Reconstr Microsurg 1997;13:111-5.

8. Olding M. Reverse radial forearm flap based on an "exteriorized" pedicle. J Hand Surg [Am] 1991;16:157-60.

9. Brunelli F, Giele H, Perrotta R. Reverse posterior interosseous flap based on an exteriorized pedicle to cover digital skin defects. J Hand Surg [Br] 2000;25:296-9.

10. Jeng SF, Wei FC. Distally based forearm island flap in hand reconstruction. Plast Reconstr Surg 1998;102:400-6.

11. Moffett TR, Madison SA, Derr JW Jr, Acland RD. An extended approach for the vascular pedicle of the lateral arm free flap. Plast Reconstr Surg 1992;89:259-67.

12. Taylor GI, Townsend P, Corlett R. Superiority of the deep circumflex iliac vessels as the supply for free groin flaps. Clinical work. Plast Reconstr Surg 1979;64:745-59.

13. Chen H, El-Gammal TA, Wei F, Chen H, Noordhoff MS, Tang Y. Cross-leg free flaps for difficult cases of leg defects: Indications, pitfalls, and long-term results. J Trauma 1997;43:486-91.

14. Yamada A, Harii K, Ueda K, Asato H, Tanaka H. Versatility of a cross-leg free rectus abdominis flap for leg reconstruction under difficult and unfavorable conditions. Plast Reconstr Surg 1995;95:1253-7.

15. Topalan M, Ermis I. Cross-leg free flaps for emergency extremity salvage: Case report. J Reconstr Microsurg 2001;17:157-61.

16. Yu ZJ, Zeng BF, Huang YC, et al. Application of the cross-bridge microvascular anastomosis when no recipient vessels are 
available for anastomosis: 85 cases. Plast Reconstr Surg 2004;114:1099-107.

17. Brenman SA, Barber WB, Pederson WC, Barwick WJ. Pedicled free flaps: Indications in complex reconstruction. Ann Plast Surg 1990;24:420-6.

18. Morrison WA, Pribaz JJ. Vascularized tube pedicle: A case report. Br J Plast Surg 1980;33:25-9.

19. O'Brien BM, Barton RM, Pribaz JJ. The wrist as an immediate free flap carrier for reconstruction of the pelvis; a case report. Br J Plast Surg 1987;40:427-31.

20. Harris GD, Lewis VL, Nagle DJ, Edelson RJ, Kim PS. Free flap reconstruction of the lower back and posterior pelvis: Indications, principles, and techniques. J Reconstr Microsurg 1988;4:169-78
21. Serafin D, Shearin JC, Georgiade NG. The vascularization of free flaps: A clinical and experimental correlation. Plast Reconstr Surg 1977;60:233-41.

22. Attkiss KJ, Suski M, Hunt TK, Buncke HJ. Ischemic preconditioning of skeletal muscle improves tissue oxygenation during reperfusion. J Reconstr Microsurg 1999;15:223-8.

23. Black MJ, Chait L, O'Brien BM, Sykes PJ, Sharzer LA. How soon may the axial vessels of a surviving free flap be safely ligated: A study in pigs. Br J Plast Surg 1978;31:295-9.

24. Fisher J, Wood MB. Late necrosis of a latissimus dorsi free flap. Plast Reconstr Surg 1984;74:274-81.

25. Salgado CJ, Smith A, Kim S, et al. Effects of late loss of arterial inflow on free flap survival. J Reconstr Microsurg 2002;18:579-84. 